\title{
HUMOR Y SACRALIDAD EN EL MUNDO AUTÓCTONO ANDINO ${ }^{1}$
}

\section{HUMOR AND SACREDNESS IN THE ANDEAN INDIGENOUS WORLD}

\author{
Gabriel Martínez Soto-Aguilar
}

\begin{abstract}
El análisis de dos ceremonias -Semana Santa y la construcción de una casa- en el ayllu aymara de Isluga, ubicado en el altiplano de Iquique, saca a luz la relación especial que se establece en estas ceremonias y otras, entre aspectos jocosos y los momentos altamente sagrados. La risa y el humor se presentan como elementos que ayudan a crear la atmósfera del ritual, situándolo en un plano de otra realidad. Los elementos humorísticos están, sin embargo, altamente controlados y sometidos a momentos y acciones precisas al interior de las ceremonias.
\end{abstract}

Palabras claves: Isluga, humor, sacralidad, diablos, Semana Santa, auto sacramental.

The analysis of two ceremonies -Easter and the construction of a house-in the Aymara ayllu of Isluga, located in the Altiplano of Iquique, reveals the special relationship among jocose aspects and highly sacred moments. Laughter and humor are presented as elements that help to create the ritual's atmosphere, by placing the ceremony in a different reality. The humorous elements are, nevertheless, highly controlled and subordinated to precise moments and actions within the ceremonies.

Key words: Isluga, humor, sacred, devils, Easter, self-sacramental.

Hay un hecho que nos llama la atención en la religiosidad de los grupos aymaras y quechuas con los que hemos convivido y que nos lleva a tentar algunas explicaciones. No siendo la religiosidad el único ámbito donde aparece -más bien se da por todas partes-acaso algunas de las consideraciones que nos provoca pudieran ayudarnos a entender tanto el fenómeno en sí como elementos del pensamiento actual en los Andes.

Se trata, en primera instancia, de esa coexistencia del humor con lo sagrado, que es posible observar en varias ceremonias de la pródiga y complicadísima ritualidad aymara-quechua, y que a primera vista choca o, al menos, desconcierta.

Se nos ha hecho patente aquí en Isluga ${ }^{1}$, pero lo hemos observado también en Bolivia, en la comunidad de Lunlaya ${ }^{2}$, donde residimos varios años (Figura 1). No obstante, no nos atrevemos a afirmar su generalización en todo el mundo andino, que conocemos muy limitadamente. Si nos atreveríamos con ciertas reservas a afirmarlo como un rasgo propio de las culturas que estamos investigando: situaciones cuya religiosidad incluye el humor como ingrediente y que -nos arriesgaríamos a sospecharlo-perfecciona esta religiosidad y la afirma.

No se trata tan sólo de la irrupción imprevista y espontánea de una ocurrencia graciosa en medio de la liturgia, cuestión, sin embargo, que no está del todo desligada del hecho que nos interesa. Se trata de algo muchísimo más especial y, al parecer, significativo: una sacralidad que se vale del humor para realizarse, una sacralidad establecida también

1 Este artículo circuló en formato mimeografiado, como varias de las obras de Gabriel, más cercano y cómodo en el mundo de la oralidad que permite un afinamiento y madurez permanente de las ideas, que de lo contrario quedan congeladas en un escrito. Han pasado más de treinta años desde la impresión en la serie Cuadernos de Investigación, de la sede Iquique de la Universidad de Chile de esta propuesta desafiante que es ahora un clásico de la antropología andina, por lo que esperamos que su republicación motive, en un futuro próximo, un número especial de Chungara dedicado a Gabriel, como concluimos hace un tiempo atrás en una reunión en Arica, entre Vivian Gavilán, Tristan Platt, Jorge Hidalgo, José Luis Martínez, entre otros. El manuscrito, se "revivió" con ocasión de una convocatoria de Chungara para un número en memoria a John V. Murra, en virtud de la amistad que los unió y de los muy buenos recuerdos que Murra tenía de Gabriel desde sus épocas en Iquique, luego Lima, luego París y Bolivia.

Se agradece a José Luis Martínez por facilitarnos una copia digital y ayudarnos en la presente edición del manuscrito que se publica en Chungara, así como también a su madre y viuda de Gabriel Martínez, Verónica Cereceda, quien editó la revisión final de este artículo, en la que cuidamos no alterar el texto original de Gabriel. 


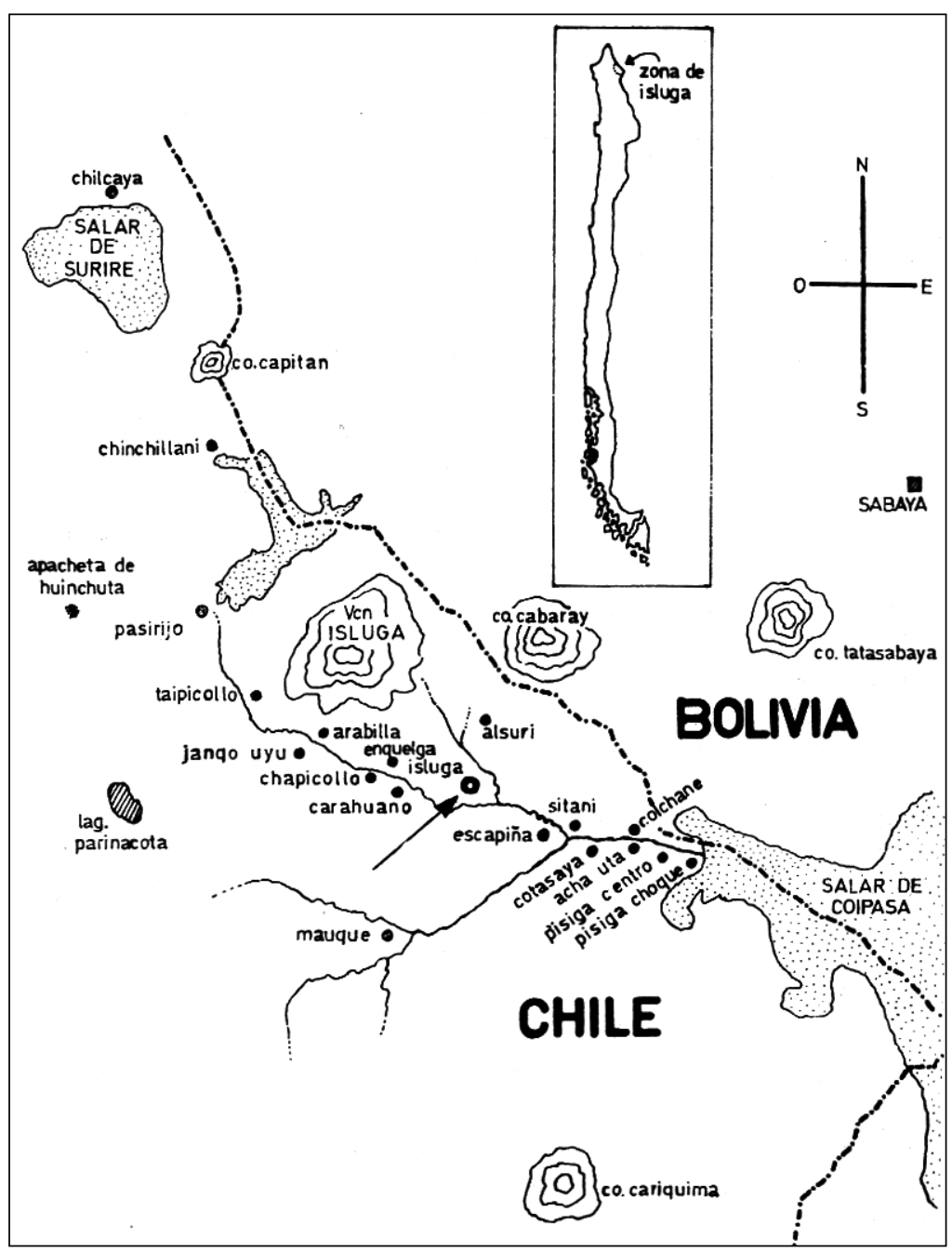

Figura 1. Mapa de la región de Tarapacá.

Map of the Tarapacá Region.

en lo gracioso con plena propiedad y libertad. Y toda vez que ello se produce como hecho ceremonial se trata, entonces, de un humor ritualizado y estatuido, integrado a la totalidad de la situación.

No es nada fácil explicarlo en abstracto. Y suponemos que aún más difícil es entenderlo para quien no lo ha observado y vivido. Por ello nos parece mejor ilustrarlo con algunos ejemplos concretos de nuestra experiencia.

\section{Los “Diablos" de la Semana Santa en Isluga}

Son cerca de las doce de la noche del Viernes Santo en Isluga ${ }^{3}$. Gran parte de la comunidad ${ }^{4}$ está en la iglesia, al modo como están siempre las multitudes indígenas, haciendo sentir esa presencia interna y casi caótica de lo oscuramente vital. Los hombres de pie, aglomerados, cabeza descubierta, conversan en voz baja o miran asombrados la maravilla deslumbrante de las decenas de velas que iluminan las imágenes y todo el altar mayor. Las mujeres, con sus anakos ${ }^{5}$ negros y sus niños de pecho, sentadas en el suelo, aparte, susurran los cuchicheos ásperos del aymara... Los pasantes, mayordomo y alferado, arrodillados ante el altar, sosteniendo erguidas las banderas de su cargo, con sus mujeres detrás... Los caciques, con sus varas ${ }^{6}$, sentados en los bancos laterales, ya repletos con niños y adultos. El mayordomo de la Comuna de $\mathrm{Abajo}^{7}$, la enorme llave de la iglesia colgada al cuello de 
una cadena, enciende velas, arregla candelabros, se afana por detrás del altar, ultimando detalles... Sólo se oye fuerte el canto litúrgico de Julián, el viejo poderante ${ }^{8}$ del pueblo, en un latín que ni él ni nadie entiende: desde un rincón, atrás, bajo el coro, sentado en el suelo y apenas iluminado por una vela, memoriza más que lee un destartalado libro de rezos, que es todo su tesoro.

De pronto, el canto se detiene. Hay un prolongado silencio. La gente mira hacia atrás, sonriente. Se nota que esperan algo. Algo que ha de ocurrir y que demora, que ya debió haber ocurrido. De pronto, se oyen recios golpes, desde afuera, sobre las gruesas hojas de la puerta de la iglesia que -no nos habíamos dado cuenta- están cerradas. A los golpes, todos ríen con expectante regocijo. La voz gruesa de Julián dice, desde su rincón, con fuerza y una clara entonación ceremonial, en mal castellano: “iAdelante, varones!”. Las puertas se abren con gran estruendo y hacen su entrada cuatro extraños personajes: claramente se trata de diablos, muy coloridos de atuendo, el rostro oculto por un pañuelo. Entran corriendo casi en fila apretada, uno tras otro, con un paso rapidísimo, arrastrado y ruidoso; se desplazan por la nave describiendo un zig-zag de muchos vértices, a un ritmo dado por el "delantero", que agita en su derecha una pequeña campanilla9, a la vez que emiten todos un raro y apagado rugido. La gente, alborozada, les abre paso con presteza, temiendo ser atropellada, hasta que llegan al altar. Hay una breve interrupción, se dan órdenes en voz baja, gente del público trae las andas. Y los diablos, sin dejar de rugir sordamente, trepan hasta donde está la dramática imagen de Cristo crucificado y, sin contemplaciones, proceden a desclavarlo de la cruz. Le quitan la corona de espinas, que alguien entrega a la mujer del alferado, y ella toma con reverencia y la mantiene sobre su seno. Lo despojan de un collar que -desde lejos no vemos bien- sugiere un instrumento de tortura que ha provocado llagas en el cuerpo del Señor ${ }^{10}$. $\mathrm{Y}$ alguien nuevamente entrega esta reliquia. Ahora desclavan el cuerpo de la imagen, que es articulada en sus brazos, codos, rodillas, como las antiguas muñecas de loza. El acto preciso de retirar los clavos de las manos sangrantes provoca en la concurrencia de la iglesia, especialmente entre las mujeres que observan, un “iAh!” conmovido, de alivio, como si la imagen se liberara de su crucifixión y descansara. Un Cristo desvalido, con sus miembros inertes, es conducido con tierna delicadeza por esos mismos diablos -que hasta ese momento han demostrado un trato tan rudo- para depositarlo en la urna, suavemente acolchada y con tapa de vidrio, que habrá de ser sacada en procesión. Decenas de otras manos los ayudan en esta tarea, entre exclamaciones de advertencias: “¡Cuidado, cuidado!” ¡”Más suave!”Ya los clavos de la cruz han sido sacados y entregados también en custodia a los pasantes.

Estamos asombrados y excitadísimos. Todo tiene el sabor de un antiquísimo auto sacramental, vivo, perfectamente vigente. Es obvio que representa el episodio del Descendimiento. Sin embargo, lo que sucede es ambiguo y desconcertante. La actuación de los diablos pasa, sin transiciones, de lo jocoso a lo reverente. Y a veces, la forma en que desclavan a Cristo sugiere demasiado un acoso, casi un martirio: gestos de una brusquedad premeditada que introducen el esbozo de una intención, acaso teológica, no lograda. ¿Se ha querido sintetizar en esos diablos de maldad tan poco convincente, la crueldad y el pecado de los hombres que motivaron la Pasión del Señor? Mientras desarman al crucificado los diablos están todo el tiempo actuando; no cesan de rugir. A veces se mueven de más, como para subrayar el plano representativo. Hay mucho alboroto jocoso, y sin embargo, en medio de él, las reliquias son recibidas con fervor y el cuerpo de Cristo es trasladado con solicitud y piedad. Todo ello más allá de la comprensión de cualquier posible símbolo. Es toda una representación farsesca y, no obstante, la sacralidad está siempre a medio filo, codo a codo con la risa.

Pero no hay tiempo de análisis y reflexiones. Los hechos se precipitan. La tropa de sikuras ya ha comenzado a tocar una bella melodía que nos llega quizás de qué tiempo pretérito. A la vez, la banda instrumental también irrumpe con una marcha que atruena el interior de la iglesia y apaga las sikuras ${ }^{11}$. Aún más débiles se oyen los lakas. Repican las campanas. En medio de esta baraúnda se inicia lo que parecería ser la procesión del Santo Sepulcro, y quienes precisamente llevan las andas altas y pesadas - con la urna dentro de la cual va el cuerpo yaciente de Cristo- son precisamente los diablos.

Ya en el exterior, en la "calle", advertimos nuevos personajes en los que no habíamos reparado: dos "sacristanes", dos niños varones vestidos, quién sabe por qué, de muchachas ${ }^{12}$ siguen a los "bailes", que abren la marcha. La colocación de los músicos es rígida y perfectamente establecida: primero, las sikuras, la música ancestral y tradicional, que tiene 
preferencia. Luego, a cierta distancia, la banda. Siguen los "sacristanes". Y otro nuevo personaje, no disfrazado, pero con un palo en las manos que, ya veremos, es un instrumento de castigo. Vienen luego los diablos, con las andas de Cristo en hombros y tras ellos, cuatro mujeres llevando las andas de la Virgen, la Mamita Concepción. Detrás, siguen los pasantes, los caciques y todo el resto de la gente, incluidos los lakitas. La procesión habrá de dar la vuelta en torno a la iglesia, deteniéndose en cada una de las cuatro esquinas, donde, un poco apartado del edificio central, está el altar ${ }^{13}$ de cada ayllu.

Y aquí en la calle, vuelve a golpearnos el mismo problema, con nuevos matices. Porque ocurre que los diablos llevan la urna en sus andas con un paso ritual, que recuerda aquel de su entrada a la iglesia; pero ahora son unos cuantos pasitos rápidos hacia delante, que inmediatamente se continúan con otros tantos de retroceso ${ }^{14}$, con lo cual la procesión avanza muy lentamente. Lo más importante: este modo de llevar las andas no es mecánico. Aflora inmediatamente otra vez la presencia indudable de un sentido, que siempre esquiva toda nitidez. Pues, por un lado, se insinúa la sospecha de que, por su maldad con Cristo, han sido castigados a cargar las andas. Tarea harto penosa, en verdad, por el peso de las andas, de gruesos troncos, más la urna. En efecto, el impulso de los diablos hacia delante parecería estar preñado de rebeldía, cual si quisieran escapar desbocados, con el Cristo a cuestas. Luego, se sugiere que están sometidos a una disciplina que no pueden romper y les cuesta aceptar: son los pasos de retroceso. Pero también, por otro lado, se hace sentir que esa lentitud en el avance premeditadamente está concebida como sacrificio para los portadores, hombres y mujeres y para todos los que siguen la procesión, que deberán asumir en la penuria física de la larga y lenta vuelta a la iglesia que dura hasta el alba, parte del dolor de Cristo. Pero, ¿por qué todo ello se propone $-\mathrm{o}$ se realiza- en el plano de lo cómico y de la contradicción? Pues se produce inevitablemente lo jocoso: cada arranque de los diablos hacia delante provoca irremediablemente la risa, que de inmediato es contraatacada por el grupo de los más viejos alzando más sus voces en el canto religioso y entonando con mayor devoción la melodía.

No hay duda de que ambos elementos son parte de un juego que tiene en la contradicción de ellos el motor de su pompa dinámica. Después sabemos que todo el arte de ser diablo y llevar las andas está basado en una delicada sutileza: el diablo, "por respeto al cuerpo de Cristo", debe suscitar lo cómico, pero sin traspasar nunca las fronteras de lo grotesco. Por respeto a Cristo debe provocar la risa, pero también por respeto a Cristo debe conservar la medida. Sutileza bien difícil de mantener, porque además el peso de las andas, cada descanso en cada uno de los cuatro altares es motivo de abundantes chaltas $^{15}$ y cócteles de leche caliente con alcohol (iindispensables, por otro lado, para combatir el frío cortante de la una y media de la noche a más de cuatro mil metros de altura!). Y si bien el buen trago reanima las energías, por otra parte debilita la conciencia de la medida. El resultado es que los diablos tienden a sobrepasar cada vez más el umbral de lo permitido, con lo cual obligan a intervenir a aquel personaje que llevaba el palo en las manos, hasta ese momento mera presencia: mantiene a raya a los insubordinados e irreverentes, sin escatimar los golpes, lo cual, desde luego, realza lo jocoso, y esto provoca una nueva exaltación del sentimiento religioso ya estimulado por el alcohol. En efecto, a partir del descanso en el altar de Isk'a Ayllu ${ }^{16}$, después de haber pasado por el de Kollana Ayllu, se hace difícil no percibir en el ambiente una gradual intensificación de la carga emotiva que se ha ido produciendo poco a poco, oscuramente, en el transcurso de la noche y le da a ésta un proceso íntimo, que también nos resulta sorpresivo.

No hay nuevos elementos en lo que resta de la procesión. Los descansos en los altares de Ach'a Ayllu y Saw Juan Ayllu no han hecho sino incrementar el juego de los factores que hemos señalado y el reingreso a la iglesia termina dando motivo a una acalorada disputa verbal, en que los mayores dan rienda suelta a su enojo violento por la forma en que los diablos, siempre jóvenes, han trasgredido la norma ritual. Hay en ello un apasionamiento por un tema litúrgico que ya no nos extraña. Por lo demás, conocemos el "respeto a la costumbre" y el sentido que para los Isluga tiene el "buen cumplimiento"17. Pero, a posteriori nos asiste la sospecha de si esta discusión no es también parte del asunto. Los jóvenes "deben" romper la norma y los viejos "deben" enojarse. ¿No está todo concebido justamente para que así sea?

No escuchamos el término de la discusión en la iglesia. Cansados, nos retiramos a dormir. Son las cinco de la madrugada y hemos absorbido demasiadas impresiones.

¿De dónde salen estos diablos? ¿Por qué están ahí? Nunca habíamos sabido de ellos, y es la primera 
vez que los vemos intervenir en la festividad católica acaso menos apropiada, como es Semana Santa.

De cualquier manera, no nos parece ser una importación reciente de Bolivia. No se trata de ese diablo procedente de la Diablada orureña, tan típico y que, de un tiempo a esta parte, se le ve aparecer con mayor frecuencia en nuestras fiestas nortinas, desde la Tirana hasta el Altiplano. Se trata de otro personaje, en quien, desde el desempeño hasta su traje, pasando por la organización social que lo sostiene, se advierte una genealogía muchísimo más antigua y en cuya complejidad de contenidos subyacentes se adivinan procedencias hispánicas y autóctonas que, aunque no constituyen nuestro objeto principal, conviene considerar.

Por supuesto, lo primero que salta a la vista es su condición de "personajes de una representación". No creemos errónea nuestra primera impresión en la iglesia de estar presenciando casi un auto sacramental. Resulta inevitable recordar, ante ello, la notable habilidad de los misioneros que acompañaron la Conquista y la Colonia para manejar el elemento teatral con materiales folclóricos en pro de la imposición de un cristianismo de carácter medieval (Comblin s/f:4 y ss.), y parece indudable el origen hispánico de estos diablos en tanto personajes de dramatizaciones que en otras partes del mundo andino aún animan la Semana Santa (Fortún 1966:157). Pero así como la idea doctrinaria inicial que pudo haber tenido esta representación se ha borrado al punto de ser hoy casi indefinible, también los personajes, penetrados de elementos nativos, parecen haber perdido su fisonomía original. Aún más, un rápido análisis de resultados sorprendentes permite descubrir en ellos la verdadera naturaleza autóctona de su personalidad.

Desde luego, la actuación de los diablos está asegurada por un sistema organizativo que ya de por sí encierra sugerencias significativas. Es responsabilidad tradicional del mayordomo de Arajj Saya aportar con los diablos, obligación que, no siendo la única, no deja de ocasionarle dolores de cabeza. Su omisión sería inconcebible, ya que ello haría fracasar la realización misma de la fiesta, puede comprenderse. Pero tal responsabilidad se ve facilitada por el hecho de que los diablos son cuatro. $\mathrm{Y}$ entonces, cada ayllu, de los cuatro que conforman la organización tradicional de Isluga, aporta "su" diablo. Esto es: la persona que habrá de interpretarlo y el atuendo. Y ya este hecho del número es revelador de una concepción andina del personaje.
Nos resistimos a ver en esa cifra una mera razón de eficiencia ejecutiva. Si los ayllus fueran cinco, ¿habría cinco diablos? Si fueran seis, ¿serían seis? Pero es que no puede haber más de cuatro ayllus en Isluga, como no podía haber más de cuatro suyus en el Tawantinsuyu ${ }^{18}$. E, independientemente de eso, tampoco podrían ser más de cuatro "estos" diablos. La significación de ambos hechos correspondientes, que no es casual por cierto, se pone de manifiesto al pensar por qué las cuatro personas que los juegan no salen todas de la misma estancia a la cual pertenece el mayordomo, donde le sería mucho más fácil conseguirlos. Es que tienen que ser, por lo menos, dos de Arajj Saya (comuna de arriba) y dos de Manqha Saya (comuna de abajo).

Acaso el dato de Chiapa ${ }^{19}$ sea más concluyente. Que sepamos, ya no hay en la precordillera de Chiapa cuatro ayllus y dos mitades, sin embargo, los diablos que ahí actúan para la "fiesta" del pueblo (Asunta, 15 de agosto) son también, sugestivamente, cuatro, según informaciones aún sujetas a comprobación. Y quizás si el vacío de las dos mitades en la organización esté llenado por el hecho de que los diablos ahí parecen ser dos hombres y dos mujeres, reemplazo que, de ser efectivo, también satisfaría el sentido del arquetipo.

Pero hay algo más que también, mientras espera confirmación, avanzamos a título de mera sospecha: los cuatro diablos de Chiapa-que por varios conceptos parecen ser los mismos personajes de Isluga-fueron llamados de pasada por un informante, mallkus ${ }^{20}$, que es el mismo nombre de la misma dignidad con que se designa a los cerros. Repetimos: este dato requiere confirmación. Pero, si es así, sería en extremo importante, no sólo porque definiría una personificación del cerro deificado que hemos estado buscando, sino aún más, la definiría al parecer como una de las formas de supaya, deidad ctónica autóctona a la cual la obra misionera ha tratado de identificar con el diablo católico, sin que haya otra razón que una de política religiosa. Y si todo ello sigue siendo así, entonces los cuatro diablos de Isluga revelarían claramente su rancia estirpe andina precolombina: los cuatro ayllus estarían representados por cuatro mallkus, afirmando con su presencia la esencial identidad de lo aymara en esta fiesta.

Tan significativa es la procedencia y condición de estos personajes que nuevos aspectos no hacen sino señalar en la misma dirección.

Así, el acto de disfrazarse de diablo de las cuatro personas que los representarán, constituye 
una completa ceremonia en sí misma, realizada en la intimidad de la casa del mayordomo de Arajj Comuna. Mientras tanto, los oficios del Viernes Santo están desarrollándose en la iglesia antes de las doce de la noche, hora de entrada de los diablos, como hemos relatado (¡Hora por lo demás tan sugerente!). Tal ceremonia, al consagrar el acto del vestuario, pone de relieve la organización mítica aludida: después de que la tropa de sikuras ha tocado música, y de las chaltas de rigor, en un momento dado se alinean en dos filas, frente a frente, dejando un espacio en el medio, las personas que van a hacer de diablos, más sus acompañantes que les ayudarán a vestirse. Una fila con los de Abajo, otra con los de Arriba. Ponen deliberadamente en el suelo los bultos con los atuendos y deshaciéndolos con parsimonia extraen los elementos del disfraz.

En rigor, no hay tal disfraz como "traje" hecho, listo y preparado de antemano. Con lana y aguja van cosiendo "mantas" 21 , en torno a las piernas, tronco y brazos del actor, de modo de conformar los pantalones, cuerpo y mangas del disfraz. Se usan mantas de sólo dos colores: verde y rojo, pero en tal forma distribuidas que mientras una pierna y el brazo contrario son verdes, la otra pierna y su brazo opuesto son rojos, de modo que el total resulta constituido por cuatro partes, dispuestas en oposición, de verde y rojo. Dos pañuelos o trozos de género coronan el disfraz. Uno, a manera de mordaza, lo bastante suelta para permitir respirar al actor, cubre las facciones hasta los ojos, que quedan libres. No hay máscara, por lo tanto. Otro pañuelo, anudado en sus cuatro puntas, cubre a manera de gorro la cabeza; sus dos nudos anteriores insinúan nítidamente los cuernos del diablo.

El conjunto, una vez terminado, resulta en realidad extrañamente impresionante, y logra su propósito de inspirar un cierto terror. Lo que nos resultó, sin embargo, más notable que nada, al ver la obra terminada, fue el descubrir cómo aquí en Isluga, a miles de kilómetros de Lunlaya (Charazani), se daba también, de modo abismante, la oposición del rojo y el verde como simbolismo de los contrarios en la unidad del todo ${ }^{22}$, íntimamente ligado a personajes que, en el panteón indio, tienen vínculo con el mundo de "adentro" ("manqha pacha") y son, por cierto, de esencia numinosa. En Lunlaya era la muerte, aquí son los diablos. Explicaremos algo más esto.

Cierta vez, en Lunlaya, conversando sin propósito definido con gente de la comunidad, surgió el tema de la muerte. "¿Y cómo es la muerte?", pregunté. Me dijeron: "Tiene un sombrero grande, alón; lleva pantalones de montar, polainas, espuelas. Agarra un pinkillo chico en su mano izquierda, y en la derecha un látigo. A veces se la oye desde aquí pasar por el camino de arriba, a medianoche: tiiiiín... isejjo!... tiiín (melodía del pinkillo con el tema de la muerte: tres notas agudas sostenidas)... ¡sejjo! (sonido del látigo restallando, seco, en el aire). Así va arreando un "alma" al Campo Santo (el cementerio del pueblo)...". La descripción, muchísimo más rica en quechua, creaba en verdad una imagen escalofriante. Sobrecogido, pregunté: “ ¿y cómo es la cara?" "Una mitad verde, la otra mitad roja”, fue la respuesta... Y aquí en Isluga, el diablo, presuntamente supaya, deidad de las entrañas de la tierra, es una mitad verde y la otra roja.

Las implicaciones que esto envuelve son tentadoras de sacar a luz, pero nos alejarían del tema, y nuestro propósito sólo ha sido señalar algunos elementos que muestran la verdadera faz oculta de estos personajes, debajo de su apariencia española, haciendo pensarlos inevitablemente como una expresión más del sincretismo religioso aymara y de la extraordinaria creatividad, vitalidad y permanencia del pensamiento indígena.

La comprensión de estos aspectos, sin embargo, sólo nos ayuda colateralmente a esclarecer el problema que nos ocupa, aquel de la presencia del humor en medio de lo sagrado, ya que de por sí la condición autóctona del personaje no basta ella sola para explicárnoslo. Sí, en cambio, señala lo que no podría dejar de ser una de las condiciones necesarias, en este caso: la apropiación de los elementos foráneos y su conversión en hecho consustancial por penetración de lo nativo, único material posible portador de sacralidad. Aún más: en este caso siempre, único material capaz de reforzar una sacralidad sólo confusamente presentida por los aymaras islugueños en la figura cristiana en torno a la cual no logra cristalizar plenamente el hecho religioso. Y único material, también, capaz de recibir las determinaciones de lo cómico-sagrado, con todo lo que ello representa para el funcionamiento del fenómeno religioso que hemos expuesto.

Es difícil sustraerse a la primera impresión de que el humor es exclusivamente provocado por el hecho de la representación y facilitado por la ausencia de un real sentimiento religioso. Al proceder así, aparte de merecer otras consideraciones, estamos justamente poniendo el dedo en la llaga. No cabe 
duda de que, en efecto, el tratarse de una representación, un hecho teatral, suscita decisivamente la reacción jocosa. Pero, ¿por qué necesariamente hemos de entender la risa como excluida y excluyente de la sacralidad? En el bien entendido de que se trata de una sacralidad ya establecida, que no es de por sí la experiencia numinosa misma, y en el bien entendido también que se trata de "esta risa", la risa indígena, carente de ironía o de otros contenidos destructivos y, en cambio, significativa de una fuerte emocionalidad dentro de la cual la risa y el llanto no son dos polos separados por un abismo y en la cual el deslizamiento de una en el otro, o viceversa, está permitido por la delicadeza de la expresión: jamás esta risa es estruendosa ni el llanto melodramático. No son descargas, sino "modos" de la emoción y el sentimiento. ¿Acaso de "un mismo" sentimiento?

El problema. No obstante, no es uno básicamente psicológico. Y, desde luego, no es un problema de ellos, de los aymara de Isluga. Es un problema nuestro, de imposibilidad de comprender "representación-humor-sacralidad" en estas ceremonias con nuestras categorizaciones, nuestros conceptos, con nuestros valores. Pero nuevos ejemplos quizás nos ayuden a entender mejor las cosas.

\section{Ritos Finales en la Construcción de la Morada}

En todo el ámbito quechua-aymara la construcción de la vivienda es uno de los espectáculos más conmovedores y más pródigos en material sobre las formas autóctonas que toma la sacralización del espacio. Con diferencias locales, la significación fundamental de los contenidos es la misma. Ya que nos proponemos examinar este tema en trabajo aparte ${ }^{23}$, tomaremos ahora sólo aquellas ceremonias con las cuales finaliza la construcción de una casa, que es precisamente donde más vivamente se da la temática que aquí nos interesa. Conviene puntualizar, sin embargo, que toda la labor de erección de una vivienda y, en especial, de techado, está intensamente acompañada por ritos de construcción, desde que comienza hasta que termina. La finalidad de todos los cuales, desde luego, incide en el afán central de consagrar el espacio profano para darle a la vivienda la naturaleza de lo real, haciendo de ella la recreación de un microcosmos planteada en el espacio y el tiempo míticos de la creación original (Eliade 1954:345 y ss.). Lo que llama aquí la atención, no obstante, es la sobrecarga de estos ritos, que sugiere una especial tensión espiritual de los que construyen las casas respecto a estos arquetipos.

Sólo por casualidad llegamos ese anochecer a la casa de Renato, el mallku de Arajj Saya de ese año, en los momentos en que acababa de terminar el techo de una nueva habitación en su vivienda de Junt'u Uma ${ }^{24}$. Nos conocíamos ya y nos recibió con la amable y señorial hospitalidad de los aymaras de las alturas. Como las casas en la región de Isluga también se construyen y, sobre todo, se techan con el sistema del $a y n i^{25}$, no nos extrañó encontrar ahí amigos que habían venido, al igual que nosotros, de estancias de mucho más abajo. Ello nos ayudó a sentirnos, muy desde el comienzo, en un ambiente de confianza y cordialidad. Después de ch'allar convenientemente la mesa de kawilto $^{26}$, y a poco de habernos instalado ya a departir, se introdujeron todos los elementos para la "boda", la comida sacrificial que inevitablemente va ligada a toda wilanch ${ }^{27}$. Traíamos hambre, y nos costó esperar a que Ruperto, que oficiaba la boda, diera comienzo a ella. Pero muy pronto los sabrosos trozos de carne asada que a cada rato nos alcanzaba el poderante con gentileza, más las papas cocidas, el tonqo mut' $i^{28}$ y el alcohol infaltable, nos pusieron en "estado de felicidad". Sin dejar de conversar, pese a nuestro aymara entonces bastante deficiente, nos dedicamos discretamente a observar. Estábamos contentos, además, porque aunque no era la primera vez, conocíamos poco el ritual de la boda, que no se estila en las quebradas quechuas bolivianas, donde muy raramente se practica la wilancha, propia de los pastores aymaras ${ }^{29}$. La escena no deja de ser impresionante: ahí, apenas iluminado por la lucecita de un mechero a kerosene puesto en la pared, unos diez hombres más o menos -las mujeres están ligeramente aparte- rodean por tres costados la merienda distribuida sobre un poncho extendido en el suelo. Algunos, sentados en el poyo de barro pegado a la pared, en el sitio de honor, junto al dueño de casa y al poderante. Los más, encuclillados al modo indígena en los otros dos costados, se sirven el mote y las papas colocadas en medio del poncho, por propia iniciativa. Pero deben esperar que el poderante, atento a la situación, les pase con la mano algunos de los trozos de carne asada y les invite a servírsela. Este gesto del oficiante se considera una atención, tanto más cuanto que la carne dispuesta son bocados delicados: interiores del animal sacrificado, costillas, partes tiernas. El oficiante debe velar por que 
nadie se quede sin comer carne. Naturalmente, no hay platos ni cubiertos, y esto contribuye a hacer imaginar una escena casi del tiempo de las cavernas: rostros pétreos, ojos oscuros, brillantes, manos que trituran huesos... la conversación entrecortada deja oír el ruido de carne desgarrada, chasquidos de carne masticada. Sólo en el centro de la habitación baila una luz macilenta en medio de las sombras. Algo más allá, el grupo confuso de las mujeres, que también comen, se funde en la oscuridad del resto del cuarto. Y más allá aun de las paredes, el silencio helado de las estrellas en el cielo transparente de una noche de altiplano.

De pronto, sin haber notado cómo empezó, un anticipo de nuestro tema: Vemos que Ruperto, tratando de desgarrar un trozo de carne con manos y dientes, emite un graznido, repetido varias veces, con una especial actitud corporal. Todos ríen suavemente, divertidos. Varios lo siguen. Nos damos cuenta en el acto de que están imitando al cóndor en la operación de comerse una presa, tan vívida es la imitación. Y esto -tal vez mera reacción personaljunto con aumentar el primitivismo vital con que sentimos toda la situación, refuerza en nosotros el carácter ritual de la cena, que ya toca a su fin.

En medio de los agradecimientos que pide la cortesía aymara, tampoco escuchamos el comienzo del próximo episodio, que sí nos enfrenta de lleno con el problema. Sin saber cómo, nos encontramos afuera, en la noche, junto a la casa nueva que se ha terminado no hace mucho de techar. Hombres y mujeres han salido alegres, aquéllos premunidos de algunas herramientas de trabajo: palas, picos y chuzos. Y en la primera esquina exterior de la casa, el "patrón" (el dueño de casa), su mujer y el poderante, ch'allan la esquina y queman copal ${ }^{30}$ a los grandes mallkus de Parajalla, con seriedad, casi con unción. Todos ch'allamos. Pero acto seguido comienza algo que obviamente es casi un juego ritual y que por primera vez presenciamos: los hombres hacen una parodia de construcción de la casa con las herramientas que han llevado. Imitan la tarea de hacer barro, de cavar cimientos, de levantar paredes. Todo ello acompañándose de un canto, a capella, cuya letra es dada por uno solo, coreado en ciertas partes por los demás. La canción, en aymara $^{31}$, con traducción no literal en castellano, es como sigue:

Solo: $\quad$-Achokallo, chaykullalla... la casa está terminada, hermanita...
Todos: -Achokallo tiwt-te, chayku-llalla... la casa está terminada, hermanita

Solo: -Costaner patronam jarapipamay las costaneras son como las costillas Chaykullalla del patrón, hermanita...

Todos: -¡Ia, ía!

¡Ia, ía!

Solo: -Saír patronam wejjro charpamay, las vigas son como las piernas chaykullalla... chuecas del patrón, hermanita...

Todos: ¡Ia, ía! ¡Ia, ía!

Solo: -Waskill patronam lak'utpamay

Las huasquillas ${ }^{32}$ son como el pelo

Chaykullalla...

del patrón, hermanita...

Aquí, ahora, los hombres gritan pidiendo, en broma, materiales y herramientas de trabajo, tal como se grita en la construcción real de una casa.

Unos: -¡Waskilla, waskilla! ¡Huaskilla, huasquilla!

Otros: -¡Escalera, escalera! -iEscalera, escalera!

Otros: -¡Lampa, lampa! -iPala, pala!

Otros: $\quad-i \tilde{N} e q ' e, \tilde{n} e q$ 'e! -iBarro, barro!

Ciertamente, esta parodia de construcción produce alborozo, risas. En medio de ellas, el patrón atiende con trago caliente pidiendo qaman tayk ch'alltañani, "chaltaremos, por favor, la madre casa". La misma ceremonia, con ofrenda de copal a los mallkus, mímica, canción y ch'allakus, se repite en las cuatro esquinas. Y cada vez la seriedad al "copular" cede tranquilamente lugar a las risas de la canción, con las cuales, sin embargo, nunca se confunde.

La ceremonia no termina aquí, con la consagración de las cuatro esquinas. La gente, cada vez más animada, sigue a los dueños de casa al interior de la nueva vivienda. Y ahora sí, un último rito da por finalizada la construcción: el poderante y la pareja dueña de casa consagran la entrada, cosa que ya habíamos visto en otras oportunidades, pero el tratarse de una vivienda nueva realza la significación conmovedora del hecho: la sacralización del 
umbral, del límite entre espacio exterior, heterogéneo, profano, y el espacio interior, homogéneo, sagrado (Eliade 1954:348). Una frazada, una de esas bellas frazadas de colores deslumbrantes, extendida en el suelo, al lado interior de la casa, define aún más la naturaleza trascendente de ese espacio. De rodillas sobre ella, después de las invocaciones del oficiante, mirando a través de la puerta abierta hacia el exterior, marido y mujer rezan, sosteniendo en alto el braserillo donde humea el copal y ch'allando alcohol puro del puchuyle ${ }^{33}$. Lo hacen dos veces: una para "el Dios", otra para el mallku, en sabia dualidad de reverencia. Termina la ceremonia, pero no así la fiesta, que recién empieza.

Este nuevo ejemplo, quizás mejor que el de los diablos de la Semana Santa, señala bien el hecho que nos ocupa: aquella especial participación del humor, de lo gracioso, en una situación que, en nuestro ámbito cultural, lo rechazaría de plano como factor de profanación. Sin la intervención de elementos hispánicos que dificulten, con un material casi exclusivamente, si no totalmente, autóctono, el asunto se muestra con mayor claridad. ¿Cómo es posible que lo jocoso pueda no sólo coexistir sino aún más, formar parte, incluso ser portador de lo sagrado? La parodia de la construcción lo indica, en especial la canción. En apariencia es sólo una canción burlesca, que compara en broma algunos elementos de la casa con partes del cuerpo del "patrón": las costaneras del techo con las costillas, en su regularidad; las vigas, que en esta región son de troncos de queñua, muy retorcidos siempre, con las piernas chuecas del dueño de casa; la wasquilla, con la pelambrera desordenada de la cabeza. Y, sin embargo, cuando tiempo después preguntamos qué quería decir achokallo, nuestro informante nos dijo que era la canción o aire para la casa recién terminada de construir, y agregó: "es una canción de kawilto, para dar poder a la casa". No es, pues, algo tan inocente. Sin dejar de ser una broma, una chanza $-y$ es esto, justamente, lo notable y peculiar del hecho: su polivalencia y elusividad-no es solamente eso. Aún más. Siempre sospechamos que debajo de lo burlesco, la comparación de la casa con un organismo tampoco era tan inocente: recordaba demasiado la identidad de la cosmología con la embriología, la concepción de la Tierra como organismo de la Madre (Elíade 1961:187), (la Pacha mama aymara-quechua),y la concepción del cerro como organismo humano (la "ceja" del cerro, la "nariz" del cerro, etc.) Esto es, la identidad del ser todo en el universo. Y la casa -microcosmos, organismo, madre (qaman tayka)- dentro de ello, no podía menos que participar de esta esencialidad de condición.

La canción ilumina la parodia, y ambas iluminan el arquetipo. Y aquella tensión interior que adivinábamos en la sobrecarga de ritos de construcción no parece ser sino la intensa nostalgia del retorno a aquella identidad, que aspira a lograrse en la realización de las "formas transcendentes".

Pero ¿por qué se vale de una parodia, de una representación farsesca? Nos parece que, precisamente, "debe" ser farsesca en el sentido de su no naturalidad. La cultura aymara-quechua no concibe el "realismo" como una expresión de lo real bajo un aspecto de naturalidad. Lejos de la conceptualización y duplicación de mundo que ésta supone, ya sabemos cómo para el pensamiento mítico lo real, lo verdadero no es lo natural, sino lo sagrado, y una de las funciones de la representación es, justamente, establecer y reiterar el plano propio, la condición diferente a lo natural, a lo profano, de aquella sacralidad que se quiere señalar. Nada mejor para ello que la exageración expresiva. Ante una representación teatral nuestra, un espectador aymara entraría en grave desconcierto: si ella es "muy buena" desde el punto de vista de nuestros valores, creería que lo que está contemplando ocurre en realidad, y por lo tanto no percibiría la intención de la idea con la que procuramos revelar la verdadera realidad de lo representado. Ello, en caso de que pudiera manejar tales malabarismos. Sólo las imperfecciones en el desempeño de los actores le harían sospechar que todo aquello no es cierto. Pero en este caso tampoco entendería la necesidad de todo ese aparato teatral.

Pero, ¿por qué lo cómico?, y ¿por qué no, lo cómico? Ya hemos dicho. Lo sagrado, nos parece, no es ni serio ni cómico: es sagrado, lo real. Es otro plano, otro nivel de ser, distinto del profano. Pero en ambos, tenemos la impresión, pueden darse éstas y la totalidad de las manifestaciones sin romper la naturaleza del hecho. Lo profano, no por ser serio deja de ser profano. Y cuando la cosa se plantea en el terreno de la experiencia numinosa misma, mucho menos cabe enfrentar una exigencia de definición perentoria entre dos categorías absolutas; tan propia de nuestra afición a las dicotomías: la vivencia de lo sagrado es la vivencia de la contradicción misma y de su síntesis en un estado nuevo, por completo indefinible. Ya se sabe: es lo aterrador y a la vez lo fascinante; es lo 
destructivo y a la vez lo constructivo. Es la muerte y también la vida. Es lo que es, que es también todo lo que no es. De ahí que la canción pueda ser cómica y a la vez tenga valor sacramental, sin excluir de ningún modo otras posibilidades ${ }^{34}$. El pensamiento autóctono, en verdad, está mucho más cerca que el nuestro de tal experiencia de esencialidad. Y sospechamos -no sólo en lo personal- si no es precisamente esta orfandad nuestra de lo trascendente lo que nos hace involuntariamente exigir para la sacralidad aquella seriedad que se nos antoja el clima necesario para el advenimiento de aquella experiencia definitiva, pero que el indígena no la necesita en la misma forma, pues la vive casi a cada instante como condición misma de su existencia.
Hemos tocado el tema desde algunos ángulos. No son los únicos posibles, desde luego. Por otra parte, hemos tomado sólo dos ejemplos, pero los casos son incontables: recordemos la venta de la "baratilla", al término de un alferado en Isluga, el símbolo del centro en Lunlaya, las ceremonias contra el granizo, entre los aymaras del Titicaca, etc. Material interesante que aportaría nuevos datos para comprender mejor esta problemática, pero que no podemos incluir ahora, y que tal vez salga a la luz en otra oportunidad. Por todo ello preferimos considerar que el tema queda abierto a nuevos aportes que nos permitan una comprensión más honda del pensamiento en nuestro mundo andino de hoy.

Iquique, 30 de mayo de 1974.

\section{Referencias Citadas}

Comblin, J.

s/f Valoración Cristiana de las Religiones Nativas o Sincretismo Religioso. Ed. Cedi, Oruro.

Eliade, $\mathrm{M}$.

1954 Tratado de Historia de las Religiones. Instituto de Estudios Políticos, Madrid.

1961 Mitos, Sueños y Misterios. Cía. General Fabril editora, Buenos Aires.

Fortún, J.E.

1966 Facetas tradicionales de Semana Santa. En Archivos del Folklore Boliviano $\mathrm{n}^{\circ} 2$, La Paz.

Henríquez, A.

1973 Organología del Folklore Chileno. Eds. Universitarias de Valparaíso.

Inca de la Vega, G.

1967 Comentarios Reales de los Incas. T. I. Cultura Popular, Lima.
Kusch, R.

1970 El Pensamiento Indígena Americano. Ed. José M. Cajica Jr. S.A., México.

Lara, J.

1969 La Literatura de los Quechuas. Librería y Editorial Juventud, La Paz.

Monast, J.

1965 L’Univers Réligieux des Aymaras de Bolivie. Institut de missiologie de l'Université d'Ottawa, Ottawa.

Paredes, R.

1963 Mitos, Supersticiones y Supervivencias Populares de Bolivia. Ed. Isla, La Paz.

Tschopik Jr., H.

1952 The aymara. En Handbook of South American Indians, editado por J.H. Steward, pp. 501-573 . Bureau of American Ethnology, Bulletin 143(2). Smithsonian Institution, Washington D.C.

\section{Notas}

1 Isluga, distrito del Altiplano tarapaqueño, en la frontera con Bolivia, Depto. de Pisagua, Provincia de Tarapacá, se extiende desde el límite con el Depto. de Arica, por el norte, hasta Cariquima, por el sur. Abarca parte de la Cordillera de los Andes y del Altiplano propiamente. Población aymara, de aproximadamente 2.000 habitantes, concentrada en pequeños caseríos (estancias) que oscilan desde las $10 \mathrm{o}$ 15 familias hasta los de 30 a 50 familias, habitando alturas entre los 3.800 a 4.500 msm y más. Temperaturas de -20 grados en invierno, época de lluvias intensas en verano. Economía pastoril-agrícola de autoconsumo basada en el cultivo tradicional de la quínoa y la papa y en el pastoreo de ganado auquénido y ovino. Trashumancia con ganado siguiendo el régimen de pastos de la precordillera. Intercambio basado en el trueque con las quebradas de Chiapa y Camiña y con Bolivia. Relaciones administrativo-políticas con la
Costa. Pese al proceso de aculturación es un sector bastante "puro" en comparación con otros sectores altiplánicos. La artesanía es notable por su belleza y conservación de elementos tradicionales. Aquí se desarrolla desde hace un año y medio un programa de investigación a cargo de la Sede Iquique de la Universidad de Chile: del Programa de Artesanía Aymara de Sercotec-Iquique y del Depto. Agrícola de Corfo-Iquique: el Plan Altiplano.

2 Lunlaya, comunidad quechua de la zona Callawaya, en Bolivia, Depto. de La Paz, Provincia Bautista Saavedra.

3 Nos referimos aquí ahora no al sector sino a pueblo Isluga: Isluga, por abreviar. "Pueblo"-en castellano-por antonomasia. Isluga Marka, en aymara. Cuando se dice "voy al pueblo" (Mark saraña, aym) se subentiende que es a pueblo Isluga.

4 En el sector de Isluga la organización simbólica autóctona está todavía plenamente vigente en el plano religioso. 
Está dividida en las dos mitades típicas del mundo andino (Tschopik 1952:501 ó 139-573; Kusch 1970:196, 214): Arajj saya o Arajj comuna (comuna de arriba) y Manqha saya o Manqha comuna (comuna de abajo; en estricto rigor "manqha" es "adentro"). Como se ve es el mismo esquema de Urin Qosqo y Janan Qosqo, Cuzco de abajo y Cuzco de arriba (Inca de la Vega 1967:103). El "saya" aymara parece corresponder al "suyo" quechua, en el sentido de "territorio". Hay, pues, dos sayas, dos comunas, que en conjunto conforman la "comunidad" de Isluga. Cada mitad está dividida en dos ayllus. Hay, por tanto, cuatro ayllus. Las veinte y tantas estancias que hay en la zona se distribuyen según genealogías tradicionales, en estos cuatro ayllus. El "centro" de la región es pueblo Isluga, pero aquí no vive nadie de modo permanente; generalmente el pueblo está casi vacío. Cada familia, cada estancia, sin embargo, tiene aquí su casa, pues todo el mundo acude a las siete u ocho grandes fiestas que se suceden a lo largo del año. Marka es, pues, más que nada, un centro ceremonial y el corazón espiritual de la región.

5 El anuku o ajsu es el traje femenino tradicional, de lana de alpaca, grande y pesado, pero muy abrigador, es siempre de color negro o café oscuro.

6 De acuerdo con la organización tradicional ya indicada, en Isluga se eligen, cada año, dos caciques o mallkus: uno de Arajj comuna, otro de Manqha comuna. El cargo es, más que nada, de carácter religioso, pero conserva también algunas responsabilidades y atribuciones frente a problemas de importancia colectiva: arreglos para el pueblo, construcción de caminos, canales, etc. El cargo de mallku es la dignidad más alta a la que puede aspirar un hombre de Isluga.

El símbolo de mando de los caciques son las "varas", el "Santo rey", así en castellano; no hay nombre ritual aymara para ello, dada su procedencia hispánica. La vara, de madera de chonta con argollas de plata, es un objeto de los más venerados, al cual se rinde culto y tiene todo un ritual especial, con oraciones propias, etc. La vigencia de la vara es casi general en todo el mundo andino.

7 Junto a cada cacique se elige también un mayordomo. Hay, por tanto, cada año, un mayordomo de arriba y otro de abajo. También se trata de cargos religiosos, un escalón apenas más abajo que el mallku. Se reparten las responsabilidades entre ambos mayordomos, según tradición. Estos dos personajes, mayordomo y cacique de cada saya, no tienen nada que ver con la pareja de pasantes específicos de cada fiesta, un alférez o alferado y un mayordomo. Mientras éstos enfrentan responsabilidades limitadas a la fiesta concreta que "pasan" (comida, bebida, música, oficios religiosos, principalmente) aquéllos responden de los mismos ítems, pero en las cinco más grandes fiestas del año, particularmente en la última, la más grande de todas, para Santo Tomás Patrón, Señor de Isluga, sin dejar por ello de atender también en las fiestas más chicas, pero sin mayor responsabilidad. Tanto caciques como mayordomos llevan algunas prendas de vestuario de carácter ritual para las fiestas.

8 El poderante o fabriquero, lo dicen así, en aymara, es un verdadero sacerdote autóctono, con un estatus bastante institucionalizado. Corresponde a lo que en Bolivia son los yatiris, yajach runa, etc. (Paredes 1963:21; Monast 1965:209 y ss.), según la región, aunque para el aymara de Isluga el yatiri encierra otras implicaciones, casi de mayor dignidad que el poderante. Por supuesto, el poderante agrega a sus funciones sacerdotales las de mago, adivinador, consejero $\mathrm{y}$, a veces, aunque no siempre, las de qollantiri (médico). Tampoco es el único en detentar la sabiduría. En ciertas estancias es un cargo electivo, en otras es hereditario. En el caso que citamos aquí, el poderante agrega a sus funciones las de cantor. Julián, por muchos conceptos admirables, tiene una memoria notable, canta en latín y, además, realmente "sabe". No es el único.

9 Es la misma campanilla que usan los "guías" y a veces los "caporales" en los bailes de la Tirana (Henríquez 1973:86).

10 ¿Se trata de potencias?

11 Los sikuras son, en rigor, un estilo o género musical autóctono, que se interpreta con sikus, las zampoñas que todo el mundo conoce. Aunque los lakas o lakitas también usan zampoñas, aunque más pequeñas, es un género musical muy distinto a las sikuras, siendo el primero, obviamente, de mayor calidad musical y valor autóctono. Hay diferencias entre la zampoña de sikura y de lakita.

12 Al parecer por las polleras que sugiere el sacristán...

13 Una pequeña capilla.

14 Sabemos que también en Mamiña, para semana Santa, se llevan las andas de modo parecido. En Pica, nos han informado, el paso es lateral. Nos preguntamos: ¿tiene el mismo sentido que parece tener en Isluga?

15 La challa o chalta es una castellanización del aymara ch'allaña o ch'allt'aña, nombre que se da al rito de consagración: aspersiones de alcohol puro sobre lo que se quiere consagrar -los cerros, una casa, la mesa sacramental del hogar, una cosecha, una máquina nueva, etc.- y no siempre a la Pacha mama, como generalmente se cree. Después de las aspersiones se bebe un trago de alcohol, que siempre debe ser puro. El ritual es complicado y siempre va acompañado con oraciones u ofrendas (en quechua ch'allay, ch'allaku).

16 Los cuatro ayllus de Isluga son los que se mencionan: de abajo, Kollana y Saw Juan (no San), de arriba, Isk'a y Ach'a Ayllu (el chico y el grande).

17 "Buen cumplimiento": fórmula ritual que expresa no sólo la realización de los deberes religiosos sino también el respeto riguroso al ceremonial, pero haciéndolo con amor y por amor a la divinidad.

18 Tawantinsuyu, en quechua, los cuatro suyus, el Incario. Al referirse a la distribución geográfica de los cuatro suyus del imperio, lo hace también en el sentido simbólico de las cuatro esquinas del mundo (Kusch 1970:17).

19 Chiapa, pueblo precordillerano de Tarapacá, en la quebrada del mismo nombre. Su mallku es el Tata Qhachura, cerro de gran poder, pero temible por su malevolencia. Es posible que los cuatro diablos de Chiapa estén vinculados al Tata Qhachura u otros cerros circundantes. Véase también nota 20.

20 La palabra mallku, en el aymara de Isluga tiene connotaciones sumamente interesantes. Designa un jefe, y ya hemos visto llamar así a los caciques de Isluga. El jefe de una bandada de cóndores es el conocido Kuntur mallku. Al cóndor se le dice en algunas partes mallku, por antonomasia, pero hay en ello una atribución, más que nada, de una dignidad y también una deificación: los cerros son mallkus y, sobre todo, mallku designa un prototipo que, por tanto, es sagrado. En este caso va generalmente acompañado de su 
correspondiente femenino t'alla, pero explicarlo más nos alargaría en exceso.

21 La manta es una prenda del vestuario femenino, del tamaño de una llijlla o de un rebozo pequeño. Se coloca en la espalda. De colores vivos, está hecha generalmente de castilla. Algunas están bellísimamente bordadas. Es prenda de lujo, generalmente de procedencia boliviana o peruana.

22 Significación que nos fue sabiamente sugerida por Rodolfo Kusch, filósofo argentino, estudioso del pensamiento indígena, cuando le dimos a conocer esta imagen de la muerte. La identidad de este símbolo con el dragón rojo y dragón verde de los principios chinos del yan y del yin (Paredes 1963:66 y ss.), o con el diagrama del T'ai-ki, del taoísmo, es quizás lo más notable de todo esto.

23 "Espacio sagrado en Isluga", en preparación.

24 Junt'u Uma es un pequeño caserío, cercano a unas aguas termales (de ahí Junt'u Una, "agua caliente”, en aymara), en la pampa de Parajalla, muy alta y muy frígida, casi en el límite con el Departamento de Arica; nota de los editores: actual comuna de Colchane, Provincia del Tamarugal.

25 Ayni: sistema tradicional autóctono de trabajo cooperativo aplicado a todo orden de labores (agrícolas, ganaderas, de construcción, etc.). El trabajo con que una persona ayuda a otra compromete a esta última que debe devolver la colaboración en la misma forma cuando sea requerido. El ayni forma, a veces, un complicado sistema de obligaciones (Kusch 1970:220).

26 La "mesa de cabildo" (kawilto mesa) es algo así como el altar doméstico de cada casa. Kawilto es siempre un lugar cargado de sacralidad. Sugiere un punto creacional y, por tanto, un centro. Kawilto puede haber en un cerro, o ser el cerro mismo. Puede haber en una pampa, en una chacra, en el bofedal o en un corral de ganado. En todo espacio debe haber, o puede haber kawilto. Toda casa, como lugar sagrado que es, tiene kawilto, y es el lugar sagrado por excelencia de ella, donde se realizan todas las ceremonias importantes. En Lunlaya podía estar en cualquier parte y había que buscarlo con el yatiri. Aquí en Isluga es siempre una mesa pequeña, que preside la habitación principal, pero se puede trasladar. Está lleno de objetos rituales, que sería largo enumerar.

27 Wilancha, sacrificio de llama o de cordero, sacrificio de sangre, por supuesto. Conmovedor y muy complejo, es la ceremonia máxima de la liturgia aymara (Monast 1965:133 y ss.).

28 Tonqo mut'i: mote de maíz.

29 En efecto, los quechuas, que generalmente ocupan los valles y cabeceras de valles, son más bien agricultores; hay escasez de carne y no se pueden dar el lujo de matar una llama a cada rato como ocurre con los aymaras, pastores que siempre tienen ganado a disposición. Entre los quechuas, la mesa o jaywaku, "alcance", es la ceremonia principal.

30 El copal es el ingrediente básico en el ritual aymara, en tanto el incienso lo es en el ritual quechua. El copal también es muy perfumado: triturado y molido se echa sobre las brasas, en un fragmento de plato de greda que hace de brasero, expandiendo un humo aromático muy agradable. El incienso, la q'owa y otros elementos se usan también en el rito aymara, pero para otros propósitos, rigurosamente determinados.

31 Empleamos el alfabeto aprobado en el III Congreso Americano Indigenistas, La Paz, 1954.

32 La waskilla (huasquilla, en castellano) es una trenza de paja embarrada que se sobrepone al techo de Picchu (paja brava) de la casa para impedir que el viento se lo lleve. Ciertamente, sugiere el cabello hirsuto y revuelto de la cabeza.

33 El puchuyle es la botellita de vidrio de uso ritual que contiene alcohol para ch'allar.

34 En efecto, podría tener ciertos caracteres de un canto de trabajo, al modo del jaylli agrícola de los quechuas (Lara 1969:43-44). 